\title{
REFLECTING ON TEACHING AND ECOVID-19: AN AGGRESSIVE DIGITAL TEACHING TRANSFORMATION OUTBREAK IN HIGHER HOSPITALITY EDUCATION IN CYPRUS
}

\section{MICHAEL ANASTASIOU \\ INTERNAPA COLLEGE 4 GRIVA DIGENI AV, CYPRUS}

\begin{abstract}
The purpose of this research inquiry was to reflect on: (a) how the dynamics or synergies formed by the enforced and hostile transition from traditional to online teaching and learning have affected the quality of the teaching and learning process in higher vocational education institutions in Cyprus; and (b) what the impact on teaching and learning in the post COVID-19 period has been. The DigCompEdu digital literacy framework has been used to stimulate research because of its strict and clear focus on educator-specific digital competencies. A descriptive qualitative case-study research design was used to explore the experiences of teaching staff and how they dealt with the enforced transition to online teaching. In total, 32 participants from 11 CHEIs teaching hospitality-related majors were interviewed, electronically. The data saturation point was determined by the sample size of the study. The transcription and coding of the collected data was performed using NVivo 10. The first research question identified the following emerging themes: a) the externalization of tacit aspects of digital realities knowledge, b) Collective and intelligent actions in sharing knowledge and practicing digital competencies, c) Principles of learning organization and practicing, and d) Empathy and high levels of emotional labor. The second research question revealed the following themes: a) the Changing nature of teaching and learning methodologies and approaches in hospitality studies, b) Student centered and interactive pedagogical approaches, c) Digital-based knowledge management ecosystem approach.
\end{abstract}

KEYWORDS: Hospitality education, digital transition in teaching and learning, COVID-19, program design, digital literacies, teaching. 


\section{INTRODUCTION}

The existing literature suggests that previous outbreaks of coronaviruses (CoVs) are internationally well known and they were successfully managed in the recent past without major negative consequences on teaching and learning. This was evident in the decisions of the World Health Organization (WHO) to undertake no major public measure to cancel traditional teaching or closure of higher education institutions (HEIs) at the international level (Centers for Disease Control 24/7, 2013). The CoVs include the severe acute respiratory syndrome (SARS) along with the Middle East respiratory syndrome (MERS) that affected primarily Asian regions (WHO, 2020). Both viruses were identified by the WHO as threatening agents of public health, requesting immediate and serious public health measures to be controlled (Cho \& Chu, 2015; European Centre for Disease Prevention and Control, 2014; Jiang, 2009). However, the case of the latest $\mathrm{CoV}$ outbreak and COVID-19 pandemic is presenting a profound global-scale crisis, forcing all countries to implement hard public measures, containing strict curfews, prohibited family gatherings, and closing organizations, forcing work from home, and national aerospace hubs and ports (Press and Information Office, 2020). A key goal of the public measures was to prevent the spread of the virus and, hence, to control all disastrous economic and social consequences at a global level (Sohrabi et al., 2020; WHO, 2020). Unfortunately, the extent and the severe operational impact of COVID-19 has shaken not only the foundations of national and international economies and public health quality (Sohrabi et al., 2020) but also the lifestyle and living standards of all citizens (Mintel, 2020). COVID-19 has also forced HEIs to go online and use alternative teaching and learning approaches as a result of social physical distancing recommendations and regulations (Lim, 2020; WHO, 2020).

This hostile and harshly enforced transition, from traditional to online teaching, has gained momentum not only for local teaching and learning traditions and organizations of various sizes, but also for international higher education, due to the extent and duration of the outbreak. The systemic misjudgments, unpreparedness and inaction in many cases, concerning the amended conceptual digitalization of teaching and learning as alternative teaching methods in traditional HEIs, has weakened the smooth transition and incorporation of relevant technologies and learning environments in teaching (Batane \& Ngwako, 2017; Benson \& Morgan, 2013). Consequently, the term eCOVID-19 has been introduced by the study in order to describe the chaotic situation, emerging from the HEIs' enforced and hostile transition to online teaching and learning due to $\mathrm{CoV}$ 
outbreak and COVID-19 pandemic. Major issues and questions are emerging concerning the preparedness of HEIs for such a hostile transition along with its effect on teaching and learning quality. Recent studies examined comprehensively the effective transition to online teaching programs or the integrated use of digital technologies in alternative teaching methodologies in HEIs (Buchanan et al., 2013; Kukulska-Hulme, 2012; Ngambi et al., 2016; Warburton, 2009). However, a major lack in the literature has been observed concerning the case of an enforced and hostile transition to the conceptual digitalization of teaching and learning online as alternative teaching methods, particularly in times of crisis and public emergency. The current research inquiry extends the literature on understanding: (a) how the dynamics or synergies formed by the enforced and hostile transition from traditional to online teaching and learning have affected the quality of the teaching and learning process; and (b) what the impact on teaching and learning in the post-COVID-19 period has been. Following, this research paper first provides a broad review of the literature on digital literacies and transition to set the foundation on which the conceptual framework is presented. Then, the employed research methods are justified, followed by a deep analysis and discussion of the findings. Last, study limitations, implications and the future orientation of the study is presented.

\section{LITERATURE REVIEW}

\section{Digital Transformation and Online Teaching}

Digital transformation is not a new concept among HEIs as it became an operational framework for all organizations from different disciplines, striving for high performance and competitiveness (Forrester, 2015). The findings of Guinan et al. (2019), IDC (2017) and Schadler (2018) support that digital transformation of organizational operations has become even more important than economics, politics and competition in terms of operational impact. This digital transformation trend is highly evident in the educational arena as well over the last two decades (via distance learning or blended programs), and more specifically in the years 19972006 and 2007-2016, the so-called periods of networked computers for collaborative learning and online digital learning, respectively (Radianti et al., 2020; Zawacki-Richter \& Latchem, 2018. Since then, HEIs have experienced an unintentionally enforced digital transformation reality regarding implementation, not only due to quality standards and accreditation criteria, but also for improving the employability skills and career opportunities of their graduates (Jackson, 2019). The studies of Jackson (2019) and Pucciarelli and Kaplan (2016) underline the essential need for HEI stakeholders to understand the ever-changing economic and 
demanding employment landscape in order to infuse curricula with cuttingedge digital skills, aiming at the cultural birth and engagement of the digital citizens. However, the technological reorientation and the digital infusion of the programs and curricula of HEIs (Porter et al., 2020) should be designed carefully, aiming at a twofold goal. In the short run, students should assimilate digital skills for the successful completion of their studies, and in the long run acquire updated and upgraded professional digital skills, easing their entrance into the labor market (Alexander et al., 2019; Jackson, 2019; Porter et al., 2020).

According to Porter et al. (2020), such a multidimensional and multilevel transition requires three main components to be taken into consideration prior to implementation of any institutional digital initiative or agenda. The first component is related to the instructional process. Although virtual learning environments are booming as a sector (Boulton et al., 2018; Muñoz-Cristóbal et al., 2017; Radianti et al., 2020), institutional procrastination in implementing the digital transformation agenda may introduce issues related to poor institutional planning and organization actions, ineffective internal stakeholders' communication and insufficient time for preparation (Porter et al., 2020), which increases the possibility of a failure. The second component reveals community-related concerns that are primarily related to the insufficient support of the host institution in changing the teaching and learning process. Even though teaching staff's technological challenges related to managing technology for teaching as well as to create and share relevant learning materials may be faced successfully, students' self-discipline skills and digital competencies to study independently, at their time of preference and using digital technologies may make uneasy the learning process and expected learning outcomes (Rasheed et al., 2020).

Therefore, the third component is linked to the various issues emerging from technology implementation and the means used (Connolly et al., 2007; Ocak, 2011) to pedagogically complement the digital transformation process in learning and skills attainment (Kukulska-Hulme, 2012). As a process, it requires both the pedagogical and technological elements to effectively engage students and teaching staff with the digital component. These are issues mainly related to institutional responsibility for just-intime activation and training for students and teaching staff in using the available technology productively (Rasheed et al., 2020). This training should focus on the technological advancements used and the pedagogical dimension in digital communication tools to transform individual and group dynamics in interacting learning communities (Colbert et al., 2016; 
Jackson, 2019; Kukulska-Hulme, 2012; Mason \& Bacsich, 1998; Schwarzmuller et al., 2018; Solıs-Molina et al., 2018; Wang et al., 2012).

\section{Digital Learning Literacy in Students and Teaching StafF}

However, findings from previous studies clearly show that effective learning in digital environments has as an important prerequisite the digital literacy of the involved learning stakeholders of a HEI (Alexander et al., 2019; Becker et al., 2017; Blau et al., 2020; Eshet-Alkalai, 2012; Ferrari, 2012; Porat et al., 2018). Digital literacy is defined as a person's cognitive capacity and technical capability to identify, create and effectively use digital information (American Library Association, 2016). Researchers such as Alexander et al. (2019), Cramphorn (2004) and Garner and Rouse (2016) identify students' psychological factors, attitudes towards technology, self-regulated learning and flexible access to online learning resources as engaging drivers in any digital transformation initiative. In this regard, the digital transformation nourishes greater process agility and agency (Bond et al., 2018; Hildebrandt, 2019; Jackson, 2019) in order to leverage knowledge management, independent study, critical thinking and learning to learn skills (Conference Board, 2019; Jackson, 2019). The observations of Kukulska-Hulme (2012) identify collaborative training and learning teams to be energized, under such conditions, in gaining or improving personal or interpersonal digital literacy. Through their formal or informal synergies, the collaborative training teams may positively impact the isolation of personal learning and enhance the knowledge exchange process to create communities of practice that foster an opportunity for action and work-based learning (Richlin \& Cox, 2004; Kukulska-Hulme, 2012). From an implementation perspective, such an experiential learning situation creates the conditions to advance and utilize a person's digital tacit cognition in order to stimulate learning by assimilating new educational and digital literacies. In the long run, digital tacit cognition fosters a collective and practicing community culture, through empiricism and practice, which assists the formation of a culture open to change that it is capable of incorporating new literacies. Consequently, barriers related to technology know-how implementation may be anticipated, supporting the engagement of teaching staff in the digital transformation process of teaching.

\section{DIGITAL LITERACY FRAMEWORKS}

The literature provides examples of various digital literacy frameworks that have been used to guide HEIs during the transitional process to digital teaching. One example is the comprehensive edition of the Digital Literacy Framework (DLF; Eshet-Alkalai, 2012) that deals with the cognitive 
dimension along with social-emotional skills rather than technical aspects. Similarly, the framework suggested by $\mathrm{Ng}$ (2012) emphasizes the technological component and the skills needed to use technology, whereas the Digital Competencies for Citizens' Framework (DigComp2.1; Blau et al., 2020; Carretero et al., 2017) also deals with environmental protection, safety, health and well-being, which have no direct relation to digital literacies (Blau et al., 2020). However, these frameworks do not specifically and directly frame the digital literacies of educators. Due to this limitation, the current study uses the European Framework for the Digital Competence of Educators (DigCompEdu; Redecker, 2017).

DigCompEdu sets the conceptual pathway and the requirements for a balanced, achievable, well-planned and smooth transition to educators' digital literacy and comprehension, shifting the digital competencies' reality specifically to the teaching profession (Redecker, 2017). DigCompEdu (Figure 1) is grounded in the pedagogical belief of educators as learning facilitators questioning simultaneously, for institutional or selfassessment and development purposes, the degree to which educators are properly prepared and ready to facilitate teaching and learning online. Thus, it assists in determining if educators are equipped with the appropriate digital competencies to effectively perform online teaching and stimulate students' learning by securing learning quality and learning outcome achievement. Although all frameworks present, in length and in an organized, synthesized and well-justified manner, the metacognitive digital literacies of digital citizens, they have all been integrated, strategically tested and implemented by HEIs over a long and uneventful period of time, remaining untouched by the planning and execution process. There is a gap in the literature on when HEIs, under emergency and crisis conditions, have been forced to go online, as in the case of the COVID-19 pandemic. In the current study, DigCompEdu has been used to stimulate research due to its strict and clear focus on an educator-specific digital competencies structure in order to investigate educators' perspectives on digital literacies, and more specifically: a) how the dynamics or synergies formed by the enforced and hostile transition from traditional to online teaching and learning have affected the teaching and learning process; and (b) what impact there has been on teaching and learning quality and achievement of the expected learning outcomes. 


\begin{tabular}{|c|c|c|c|c|c|}
\hline $\begin{array}{l}\text { Educators' Professional } \\
\text { Competencies }\end{array}$ & $\begin{array}{l}\text { Educators' Pedagogical } \\
\text { Competencies }\end{array}$ & $\begin{array}{l}\text { Educators' Pedagogical } \\
\text { Competencies }\end{array}$ & $\begin{array}{l}\text { Educators' Pedagogical } \\
\text { Competencies }\end{array}$ & $\begin{array}{l}\text { Educators' Pedagogical } \\
\text { Competencies }\end{array}$ & $\begin{array}{l}\text { Learners' Pedagogical } \\
\text { Competencies }\end{array}$ \\
\hline$\square$ Professional Engagement & $\square$ Digital Resources & $\square_{T}$ & $\square$ Assessment & $\square_{E}$ & Learners' Competence \\
\hline $\begin{array}{l}\text { - Communication } \\
\text { - Collaboration } \\
\text { - Reflection } \\
\text { - Digital CPD }\end{array}$ & $\begin{array}{l}\text { • Selecting } \\
\text { - Creating \& Modifying } \\
\text { - Managing, Protecting, } \\
\text { Sharing }\end{array}$ & $\begin{array}{l}\text { • Teaching } \\
\text { - Guidance } \\
\text { - Collaborative Learning } \\
\text { - Self-Regulated Learning }\end{array}$ & $\begin{array}{l}\text { - Strategies } \\
\text { - Analysing Evidence } \\
\text { - Feedback \& Planning }\end{array}$ & $\begin{array}{l}\square \text { • Accessibility \& Inclusion } \\
\text { - Differentiation \& } \\
\text { Personalization } \\
\text { - Actively Engaging } \\
\text { Learners }\end{array}$ & $\begin{array}{l}\text { - Infor ation \& Media } \\
\text { - Literacy } \\
\text { - Communication } \\
\text { - Content Creation } \\
\text { - Responsible Use } \\
\text { Problem Solving }\end{array}$ \\
\hline
\end{tabular}

\section{Figure 1: DigCompEdu Competencies and Their Connections}




\section{BACKGROUND OF THE STUDY}

The conceptual framework (Figure 1) in the current study posits Cypriot higher education institutions (CHEIs) to have been harshly enforced to deliver online teaching due to the CoV outbreak and COVID-19 pandemic and ensuing school closures (IPO, 2020). This crisis and emergency situation gave CHEIs no sufficient time to plan and implement an action agenda for the digital transition of the learning process, from traditional to online teaching. Hence, no particular DLF has been used or considered for a smooth and strategic integration of the digital transformation process at an institutional level. Simultaneously, all CHEIs must fully comply with the instructions provided by the Cyprus Agency of Quality Assurance and Accreditation in Higher Education (CYQAA; 2020), to secure teaching and learning quality, learning outcome achievement and in turn a reliable, valid and objective student assessment. Consequently, this health-related and social distancing crisis (Lim, 2020; WHO, 2020) created various dynamics and synergies in the learning process to anticipate the consequences of the hostile transition from traditional to online teaching.

CHEIs, in this study, are defined as HEIs, non-university, which offer among other programs of study accredited diplomas and bachelor's degrees related to hospitality specializations, including hospitality and hotel management, and tourism and event management as well as culinary arts. These programs are accredited by the CYQAA, meeting academic and quality assurance standards of higher education in the Republic of Cyprus. Cyprus is an emerging higher education center in the eastern Mediterranean Sea, and it is characterized by the growing public and private HEIs that offer hospitality-related programs of study (Nachmias et al., 2017). However, certain challenges are still faced related to their programs' quality assurance and organizational accreditation process (CYQAA, 2020), as the input and contribution of CHEIs toward the expansion of Cyprus as a global educational center is becoming very important (European Migration Network, 2012). Hospitality-related programs of study are the educational product offered by private-owned and profit-targeting colleges (European Migration Network, 2012). According to Anastasiou (2019) and Nachmias et al. (2017), the growing number of CHEIs offering hospitality-related specializations can be supported by the Cypriot hospitality tradition and reputation as an international and recognized high-quality tourist destination.

In order to uncover the consequences, dynamics and synergies created through the efforts of CHEIs to proceed under the pressures of COVID-19 with online teaching, the DigCompEdu framework was selected. DigCompEdu provides a comprehensive framework regarding the teaching 
staff's required digital literacies for achieving an effective institutional digital transition that fully supports online teaching. Figure 1 categorizes the required digital literacies and defines each group variable that is explored in the current study. The DigCompEdu framework offered a sophisticated and inclusive approach in exploring teaching staff's digital competencies via the human, technology and pedagogical lenses, serving a twofold purpose. First, it crafted the conceptual pillars that drove teaching staff's individual stimulus and virtues to effectively respond to the harsh transition to online teaching and to secure, simultaneously, teaching quality, learning outcome achievement and reliable student assessment. Second, it helped in broadening the cognitive horizon and acquiring a comprehensive knowledge of the academic, professional and pedagogical consequences and emerging realities in the post-COVID-19 traditional and online teaching era in CHEIs.

\section{METHODOLOGY}

The DigCompEdu framework provided the opportunity to explicitly outline the focus and the thematic pathway of the study. This qualitative investigation was performed through the lens of the constructivist tradition (Lincoln \& Guba, 2013). The aim was to offer the appropriate conditions where the investigator and participants interacted in co-creating new knowledge based on their feelings, perceptions and professional experiences. For the needs of the current study, six thematic areas were considered (Figure 1): a) professional engagement, b) digital resources, c) teaching and learning, d) assessment, e) empowering learners, and f) facilitating learners' digital competence. Therefore, the inductive nature of the current study designated, due to the broad thematic headings, the exploration of the themes that emerged from participants' responses.

\section{Sampling, Data Collection And Analysis}

In the current study, a descriptive qualitative case-study research design was used to explore the experiences of teaching staff and how they deal with the enforced transition to online teaching. Securing the recruitment of and accessibility to participants was achieved through the snowball sampling process. The eCOVID-19 digital pandemic outbreak created an absolute urgency among CHEI stakeholders (CYQAA, 2020; paideianews, 2020; Press and Information Office, 2020). This situational urgency motivated teaching staff to participate in the study due to school closures and the availability of digital tools that eased researcher and participants' interactions. Thus, the researcher in many cases was introduced to snowball clusters (Griffith et al., 2016; Noy, 2008). After the introduction of the researcher to one participant's colleague, an open invitation 
email/letter was sent in order to describe and specify the nature, the goal and the objectives of the study.

The research instrument was developed according to the six thematic areas of DigCompEdu, using the two guiding questions: a) How have the dynamics or synergies formed by the enforced and hostile transition from traditional to online teaching and learning affected the quality of the teaching and learning process; and (b) What impact has there been on teaching and learning in the post-COVID-19 period? Therefore, to secure the reliability and the validity of the research instrument, the open-ended questions were piloted to 10 digital literacy teaching staff and experts with the content of the DigCompEdu. For selecting all faculty members, the criterion sampling strategy was used (Patton, 2015), based on digital literacies, prior online teaching and teaching expertise in CHEI-related hospitality management programs (Flick, 2008; Stake, 2010; Yin, 2017). Sampling and the recruitment method include risks and opportunities. It could be argued that the study opportunity to explore the teaching staff's enforced transition to online teaching due to COVID-19 and school closure could surround potential of personal bias in the expressed personal perspectives. This argument encloses a possible risk due to the qualitative nature of the current study and the non-use of a quantitative probability sampling approach. Consequently, all participants' personal status, opinions, ideas, interpretation of a phenomenon or personal experiences were treated equally in order to eliminate unreasonable claims about reductive or definitive representation of the facts and reality.

Moreover, the data saturation point was determined by the sample size of the study (Patton, 2015). In total, 32 participants (19 men; 13 women) from 11 CHEIs (13 full-time; 19 part-time) teaching hospitality-related majors were interviewed face to face, electronically. In order to reduce all internal and external threats of the study, the DigCompEdu framework was used. All in-depth interviews took place online. Participants used their personal accounts on Skype, Zoom or Teams 365, which allowed the recording of the interviews. Then, the recordings were transferred to a passwordprotected file to ensure confidentiality. The interviews took place during participants' time preferences and maintaining appropriate conditions for them to disclose their personal experiences and beliefs statements. The transcription and coding of the collected data was performed using NVivo 10, following the five levels of data analysis suggested by Denzin (2001). Emerging study themes and thematic categories were compared to the literature to explain the research questions of the study. 


\section{FINDINGS AND DISCUSSION}

This section consists of two parts, presenting the major findings of the research inquiry. In the first section, the dynamics or synergies formed by the enforced and hostile transition from traditional to online teaching and learning that have affected the quality of the teaching and learning process are assessed. The second part concentrates on the impact on teaching and learning quality in the post-COVID-19 period. All relevant information is presented according to the theme, emerging from the analysis. Verbatim quotes are used as well to illustrate and support the findings of the research.

\section{TEACHING AND LEARNING - DIGITAL TRANSITION DYNAMICS AND SYNERGIES}

\section{'EXTERNALIZE TACIT ASPECTS OF KNOWING ABOUT DIGITAL REALITIES'}

The tacit aspect of knowing was a strong theme that emerged from the analysis of the findings as twenty-three $(\mathrm{n}=23)$ participants underlined its positive impact and synergies during the enforced digital transition. Participants noted the importance of tacit knowing, emerging from their professional experiences and competencies with their industry employers that complement their professional cognition. On the one hand, educators' ambidexterity and industry and academic experience contributed to creating synergies to sustain a qualitative responsiveness to online teaching ( $\mathrm{n}=11$ ). On the other hand, participants strongly underlined the contradictions between hospitality businesses' digital operationalization needs and CHEIs' digital literacies $(\mathrm{n}=16)$. Rather, in accordance with Rasheed et al. (2020), observation, educators' initiatives and use of tacit aspects of knowing, from their professional or personal life, assisted in creating and sharing relevant digital material in managing teaching-related technologies. Hence, the study concurs with previous studies on digital literacies (American Library Association, 2016). Specifically, digital realities were linked to personal and professional related duties performed by educators in the industry, i.e. as managers or supervisors in a particular hospitality organizational setting. This was illustrated by the quotes of the following two participants.

Organizational pressures for higher productivity and performance to keep [name of the hotel] market competitiveness, showed a one-way direction towards operational digitalization. Use of online reservations, e-marketing and social media. As a result, my personal familiarity with digital tools, experience gained and competencies being developed at the workplace allowed me to externalize and diffuse important professional tacit 
knowledge to respond towards the enforced transition to online teaching. (P03; part-time educator)

I believe the changing nature of communicating overseas and doing business via Internet, with tour operators or customers, led to the introduction of online communication tools and social media use a long time ago at my workplace. My personal experience and training received in the past allowed me to know how to response to this change and adapt immediately to the requirements of online teaching, using digital tools. (P11; full-time educator)

\section{'ACT COLLECTIVELY AND INTELLIGENTLY IN SHARING KNOWLEDGE AND PRACTICING DIGITAL COMPETENCIES'}

Throughout the interviews, participants were critical of the individual contribution of each educator in assisting peers with the emerging difficulties or problems to the digital transition $(n=27)$. Their arguments confirm Blau et al. (2020) and Porat et al.'s (2018) conclusions that learning in digital environments establishes appropriate digital literacies as a major prerequisite. Participants dismissed organizational unpreparedness and lack of digital infrastructure and tools in the pre-COVID-19 period by referring to their personal and professional attributes $(n=24)$. In fact, organizational unpreparedness stimulated an interpersonal approach that activated and energized individual personality virtues to minimize the possibility of a failure (American Library Association, 2016; KukulskaHume, 2012). The statements of three participants were very clear, indicative and explanatory as to the degree of educators' contributions and in explaining that:

...at a workplace one daily necessity is to deal with your subordinates and provide all services to guests at a certain quality level, allowing no chances to say that this was not in the training manual... adapt and move on. The priority should be the guest and of course the organizational satisfaction. Find solutions, help your people to adapt and move on. Do not get stuck. Otherwise you will soon get all the blame... not the company... (P31; parttime educator)

...manage people, customers or guests, find the right solutions to any given case or problem, support your team and every day is a new day with new challenges and different problems. Come on, we cannot say... oh this didn't happen to me yesterday... It is today and we must react according to our standards and find the best possible solutions. (P01; part-time educator) 
...three things to remember when interacting with people... change, change and change... use your imagination, search for alternative options but always go for optimal and teamwork. It's you, your professionalism and reliability towards your colleagues and guests... (P11; full-time educator)

\section{'LEARNING ORGANIZATION AND PRACTICING'}

Most participants assimilated the exchanged personal tacit knowledge into their online actions and practices and utilized it as a learning vehicle in improving related personal cognitive and digital literacies. This was evident in their good quality choices and responsiveness to the quick learning of the digital tool used in their CHEI $(n=12)$. Interview findings reveal as well that major characteristics of the learning organization contributed to educators' professional capacity to maximize the tool's effectiveness and functionality without any problems during online teaching $(\mathrm{n}=22)$. The findings confirm Kukulska-Hulme (2012) and Richlin and Cox's (2004) conclusions that collaboration improves the knowledge exchange process and forms practicing communities. It seems that this internal learning process led to correct judgement and an acceptable level of literacy regarding the digital tool used that it enhanced ( $\mathrm{n}=16$ ), simultaneously, collective learning to boost autonomous technology use and good performance during online teaching $(n=9)$. The majority of the teaching staff were not digitally literate, and although Alexander et al. (2018), Blau et al. (2020), Jackson (2019) and Porat et al. (2018) consider digital literacy as a prerequisite, the contribution of personal cognition and the power of a practicing community cannot be deemed a substitute complementary to digital competencies. Three participants pointed out:

...there was an obvious obstacle, the transition from traditional to online learning. This required a common direction for all and through a collective interaction to exchange knowledge and competencies, minimize mistakes and adapt to the emergency. (P14; full-time educator)

...we had to change and we were not sure where to start. There were educators with prior experience in online teaching and they were willing to share their expertise and knowledge. They prepared short videos to illustrate the basic functions of the selected digital tool or they sent us many links from different websites. (P29; full-time educator)

...there was a pressure to respond successfully to this emergency. I had to learn new things and I was looking for colleagues that were able to show me. After the first week it was my turn to show to someone else... we then 
formed a chat room and we used to share and learn from individual discoveries. (P07; full-time educator)

\section{'EMPATHY AND HIGH LEVELS OF EMOTIONAL LABOR'}

Findings suggest that individual and professional attributes and virtues such as interpersonal reliability, individual responsiveness and empathy (n $=28$ ) were critical personal drivers in anticipating the consequences from the enforced digital transition of CHEIs due to COVID-19. Therefore, the closer to syllabus completion and final exams, the more stressful it became to keep an effective learning process, fulfilling simultaneously the designated quality assurance requirements by DIPAE $(\mathrm{n}=17)$. This also provides evidence for Porter et al. (2020) and Rasheed et al.'s (2020) arguments that the insufficient support or unpreparedness of the host institution may raise serious concerns and unnecessary urgency among teaching staff. Contrary to institutional unpreparedness, a deeper sense of responsibility was influencing and weighting teaching staff actions and reactions to online teaching; this is evident as well in the conclusions of Eshet-Alkalai (2012) concerning the social-emotional skills implications. This was mirrored by participants who acknowledged personal attachment and devotion to fulfilling their teaching duties by hiding inner emotions due to the emergency $(n=21)$. The following two statements represent the sentiment of the sample.

...even in days that I am sad or sick I do not externalize myself to ruin the day of colleagues, students or my guests at the hotel. I was disappointed with the entire situation, the lack of training and the enforced requirement that I had to go totally online to teach overnight... I am not a tech person and I had many issues with the use of technology... but I had to get the job done and support my students... A big smile and I clarified to my students that COVID-19 was not in our control and we had to protect the quality and the deliverables of our academic work... no matter if we were implementing the traditional or the online teaching process... our locus of attention had to be on the expected learning outcomes and not on the process itself. Adapt and live with it and if you need support I am available upon request. (P09; full-time educator)

...I did not like the situation at all but this was a personal issue and it should stay personal. I shouldn't express myself to my students and of course I didn't blame the institution for not being proactive. We should concentrate on the new learning process and the syllabus we had to complete... on the new reality rather than the emerging problems. (P24; full-time educator) 


\section{IMPACT ON TEACHING AND LEARNING IN THE POST-COVID-19 ERA}

\section{'CHANGING NATURE OF TEACHING AND LEARNING METHODOLOGIES AND APPROACHES IN HOSPITALITY STUDIES'}

Most participants (full-time or part-time educators; $n=28$ ) pinpointed their high concerns about the changing nature of the job's requirement in the hospitality industry and its potential need to reflect and influence modern and technology-oriented teaching and learning methodologies in HEIs. The aim is to prepare digitally competent and literate graduates to fulfill the needs of the labor market (Jackson, 2019; Radianti et al., 2020). As established, HEIs' hospitality curricula should respond to trends and market developmental needs, but overall HEIs need to re-approach and reengineer their teaching and learning methodological approaches in order to infuse digital literacies $(n=22)$ through a systemic approach. The findings resonate with the Porter et al. (2020) discussion concerning the digital reorientation and infusion of the programs' design for updating and upgrading the professional digital skills of graduates. Participants strongly argued that digital literacies should not be approached from a conceptual and isolated perspective, being implemented and taught apart as a scheduled course. They should instead be embedded through a systemic and academic methodology in teaching and learning $(n=23)$ in responding to the direct employment landscape (Pucciarelli \& Kaplan, 2016). Further questioning this emerging systemic methodology of the digital embedment of literacies in a program revealed the changing role of hospitality educators within a differing program design to cultivate a digital-based practicing culture and to prepare students to enter the labor market with full-range digital competencies.

...HEI must be technologically and digitally synchronized and updated with the relevant needs of the industry. Digital competencies and skills should be inherited in students' business and hospitality job culture... and it cannot be cultivated in one class. COVID-19 gave us a great opportunity to reflect on other things that we did not consider realistic or achievable before. (P10; full-time educator)

...gone are the days where educators were teaching computing, typing, and internet and social media in a course or in a program. Those are tools that an educator should use during teaching as well as to infuse an appetite to students to develop appropriate and transferable digital competencies. Can you realize what has happened with COVID-19? Personally, I did not have the skills before, I had never though to teach online and now I can say that I enjoy it a lot and surprisingly students liked too and together we discovered new aspects related to teaching and learning. For this reason, 
there should be a conceptual and contextual digital infusion in the way we educate young people and in preparing next generation's professionals. (P19; part-time educator)

...digital teaching inclusion and methodology and... students' digital literacies development should be considered in all courses, aspects and dimensions of the program of study. It should be a habit and a practicing culture. It is not about training students to develop digital literacies but to help them to comprehend and use them daily and help them as well in building a technology and digital-oriented hospitality business culture. The industry professional knowledge and skills requirement should become a common practicing element during studies. (P13; full-time educator)

On the contrary, only a few participants $(n=4)$ argued that the digital transition should be seen as a trend of the time:

...COVID-19 will not be around in a few months. Digital competencies are great and students should develop them. But I believe that the most effective teaching method is by far the traditional approach. (P30; full-time educator)

\section{'STUDENT CENTERED AND INTERACTIVE PEDAGOGICAL APPROACHES'}

Similarly, to the themes of changing teaching and learning methodologies, the majority of participants affirmed the unintentional enhancement and contribution of alternative teaching and pedagogical methodologies during the COVID-19 pandemic $(n=27)$. Participants designated alternative teaching and pedagogical methodologies as individual and group project and work-based, learning outcome-oriented, and strong digital-driven techniques in engaging students for more independent study and selfregulated mode of learning. It appears that social distancing created momentum in communication synergies as students had more time to be actively engaged in personalized academic work and at the same time to be well prepared and collaborate with others in fulfilling the requirements of the assigned work $(n=22)$. The findings underscore the observation of Garner and Rouse (2016) who acknowledge psychological factors and attitudes toward technology and self-directed learning as engaging drivers in any digital transformation initiatives. Participants acknowledged this individual and team learning process as an interactive learning approach for students in assimilating new knowledge and learning by doing (Conference Board, 2019). Also, some of the participants saw it as a real working conditions simulator and an opportunity to differentiate between experiential learning when it comes to soft hospitality-related skills such as teamwork, communication, people skills, decision-making, problemsolving and successful job completion $(\mathrm{n}=21)$. 
...teaching has changed enormously and the research was not COVID-19. COVID was only the cause and the spark that enforced all of us to introduce technology in teaching and improve ourselves... Technology was the reason and most likely our digital ignorance about its contribution towards individual effectiveness and productivity. (P07; full-time educator)

...personally I had no clue how to use digital tools in teaching. ...However, the enforced transition to digital realities, helped us to collaborate, support each other in order to get online and proceed with course syllabus. ... and then I realized that this was a totally different learning experience, with good and bad, that the unknown forced me and my students to actually learn how to learn by doing things... (P22; parttime educator)

...as far as we are not in class now and all shared info is found in a common drive, all needed info for the assignment or the exam is readily available. (P17; part-time educator)

...digital tools offer an opportunity via flip learning or project-based learning to maximize individual and group constructive learning. (P25; full-time educator)

...it was the first time in my academic career that I was able to combine three different teaching techniques (flip learning, project and work-based), keep control over all aspects, provide quick and straight to the point feedback (when we are online). I feel that this do it yourself and let's elaborate, collectively, on what you did... it gives the essence that the entire class is learning from each other... (P29; part-time educator)

...digital tool used offers a unique situation where the faces of all students appeared at the front-line... and guess what? Nobody could hide... they could study independently in a self-regulated manner and even quiet students started expressing themselves online and in a reflective practice... (P11; full-time educator)

\section{'DIGITAL-BASED KNOWLEDGE MANAGEMENT ECOSYSTEM APPROACH'}

A strong emerging theme concerning the post-COVID-19 era is the systemic responsibility of CHEIs to further concentrate their hospitality program design on digital market trends, course content, expected learning outcomes and developed professional competencies' cohesiveness, and thus to sustain innovation via technological infusions in their teaching $(\mathrm{n}=$ 18; Redecker, 2017). Participants $(\mathrm{n}=22)$ acknowledged that, from a student perspective, digital teaching assisted in gaining a clearer understanding and more focus on the interrelation and connection between 
the courses, confirming the findings of the Conference Board (2019) and Jackson (2019). For example, competencies intersecting classes, such as customer service and service quality courses, offered a unique and productive online interaction between the two classes for reflecting practices. Both lecturers and their students worked together to build productive experiential online learning activities $(n=19)$, helping students assimilate and benchmark the contribution of every class to the skills development process. Therefore, the new program design should be seen in the broader context of an optimal knowledge ecosystem paradigm $(n=12)$. The majority of participants acknowledged the embedded reality of digital additions and tools used in teaching and learning at an analogous industry level $(\mathrm{n}=24)$. This also provides evidence for Alexander et al. (2019), Jackson (2019) and Porter et al.'s (2020) observations concerning the reconceptualization and re-engineering of educational, operational and integrated strategies adopted in educational programs in order to sustain horizontal and deepen even more vertical professional-level skills and knowledge. eCOVID-19 and the enforced digital transition gave the stigma of a more controllable, quality work assurance and continuous learning improvements, leading to various challenges $(n=27)$. First, it appears that digital tools and literacies can set the baseline for the creation of an optimal knowledge management ecosystem, offering a cognitive and holistic dynamism to students to comprehend the functionality, interrelationship and utility of every thematic area covered in the program $(\mathrm{n}=18$; Jackson, 2019). Secondly, the knowledge management approach allows educators and students to have a comprehensive view in creating, storing and using knowledge and skills gained from different cognitive areas, repeatedly and throughout the years of studies (Kukulska-Hulme, 2012), such as food and beverage operations, housekeeping, front office operations, kitchen management, etc. $(\mathrm{n}=21)$. Last, the programs' digitalization may disseminate the utility of CHEIs' knowledge management ecosystem approach to all internal and external stakeholders, improving and motivating their professional network so as to advance the employability prospects of their graduates $(n=19)$.

...we must understand that technology goes in hand with development, progress and improvement. It's $2020 \ldots$ Why did institutions not take action in the pre-COVID-19 period towards that direction? At my hotel, for years now, we had developed and used platforms to control, check, provide information, at personal, departmental or organizational level, and assist our subordinates to become more effective and more efficient in what they do. It is a win-win situation. People are getting better and organizations more productive. Everywhere you look there is a technological touch in hotel operations. Nobody is expecting to return to 
the stone age... the same applies for all hospitality schools. (P15; part-time educator)

...if you think realistically, the service process starts with technology, e.g. online advertising and guests' reservation and it ends again with technology, check-out and a thank you email. I believe hospitality education institutions should think about it and find ways to somehow incorporate technology in their curriculum, for synchronous or asynchronous learning. (P03; part-time educator)

...students must learn and understand the operational integration of technology in hospitality businesses. You cannot control your subordinates or run behind your employees at all times or supervise the progress of an assignment in different departments simultaneously... but you can do it through technology. Students must introduce the right technology in their lives... This training starts from here, the educational institutions... And we need to find or build a systemic approach in doing so... (P08; part-time educator)

... Personally I found the COVID online teaching challenge as an opportunity for modernist rational thinking. So many webinars were organized and they enriched the online learning experience. Extremely easy and useful and we must keep it. We must structure it into a system to serve the purpose of the program in a way that selected courses make clear sense about their interrelations and how students should use and transfer the acquired knowledge and skills in other courses/classes or in the industry. (P15; full-time educator)

$\ldots$ another crisis in the future is highly probable. The engagement of hospitality educational institutions in digital transformation should be accompanied by a newer program design model that shares knowledge and expertise in a sophisticated and systemic way, internally and externally among stakeholders, in order to prepare qualified graduates for employment and become more proactive in facing not only industry competition but any form of crisis as well. (P11; full-time educator)

\section{CONCLUSION}

This study examined the dynamics and synergies created by the enforced and hostile transition of CHEIs from traditional to online teaching and learning, and it reflected on its impact on teaching and learning in the postCOVID-19 period. Drawing from a qualitative case-study methodology, the investigation advances understanding concerning the key drivers of personal and interpersonal dynamics or synergies that took place to anticipate the enforced digital transition and lack of preparedness and 
digital literacies. First, the study findings capture educators' dynamic factors such as educators' ability to externalize and to communicate in an intelligent extrovert manner their tacit aspects of digital knowing with colleagues and professional attributes as proximal to CHEIs' unpreparedness for digital learning, arising from eCOVID [Figure 2]. While educators, as dynamic facilitators, assisted in digital transition, it appears that their personal empathy and emotional labor personality virtues were strong engagement links and drivers in securing teaching quality and the achievement of expected learning outcomes. Second, the study indicates collaborating synergies among educators pertaining to problems emerging from the digital transition (e.g. learning and practicing communities, learning organization) as altering the students' interactive learning and the changing nature of pedagogy and teaching methodologies in CHEIs.

Third, the findings underline the need to reconcile the operational extension of a new hospitality curricula design to enhance blended teaching and learning and further clarify the interrelation and development of vertical and horizontal professional knowledge and skills. This emerging reality could be seen as a strong hospitality-labor market employment link, which establishes as a mindset in new curricula and learning outcome design the industry's professionals and practitioners' input in order to advance employability prospects. CHEIs could support the conceptual operationalization of the program's knowledge management ecosystem approach (responsiveness to stakeholders and changing market needs) in the post-COVID-19 period. Thus, academia and industry experts could stimulate learning and practicing communities not only at the teaching and learning level but also in coping with the industry's changing business environment. Derived from the study's findings, a distal-proximal explanation framework has been created (Figure 2) to illustrate the explanatory relationship between: (a) educators' personal dynamics that acted as a catalyst to qualitatively respond to and make decisions regarding the enforced digital transition, (b) interpersonal synergies that acted as an immune system and a knowledge exchange pool to eliminate weaknesses and potential fails, (c) program design, changing teaching and learning methodologies, and new realities; and d) a program management approach, arising from COVID-19. 


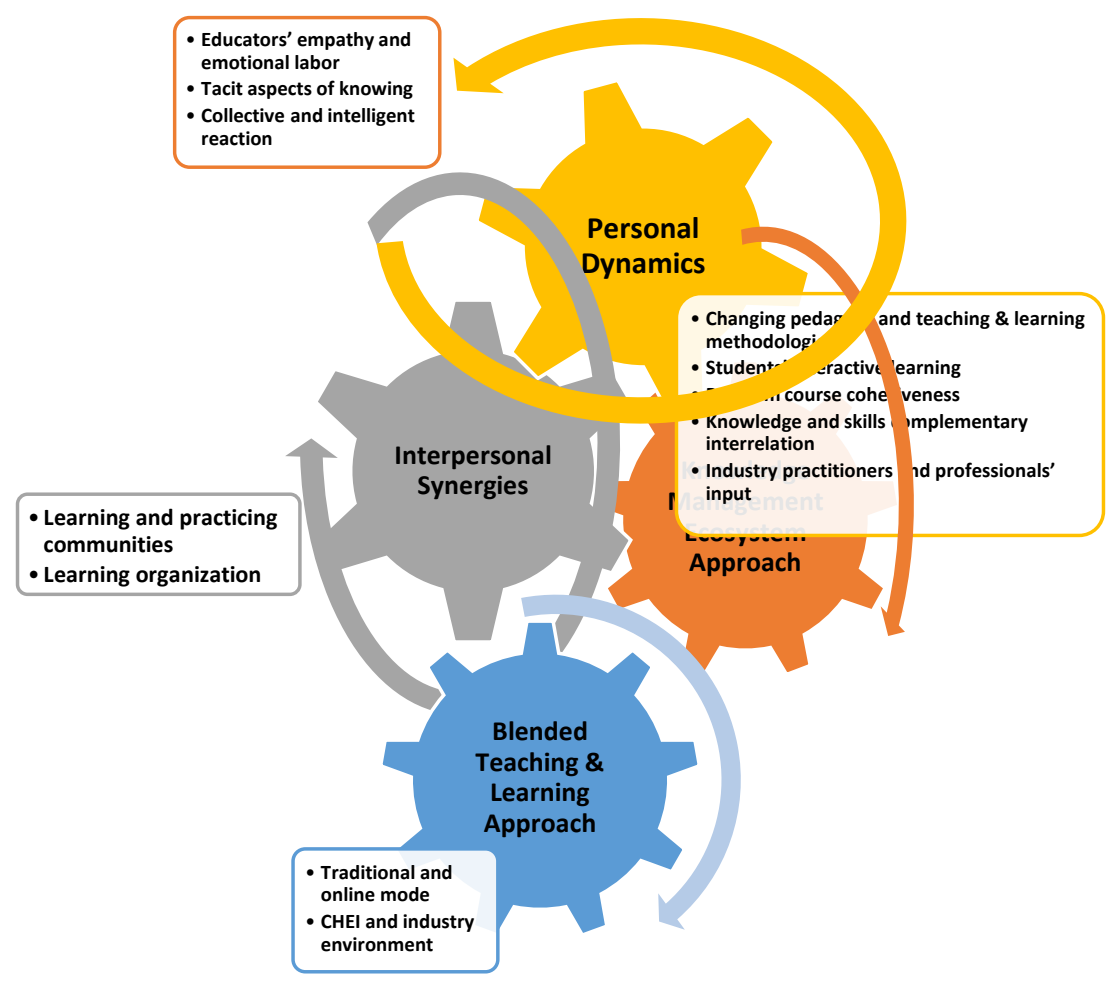

Figure 2: e-COVID Impact

\section{LIMITATIONS, IMPLICATIONS AND FUTURE RESEARCH}

This study only used and qualitatively examined educators' experiences from the enforced transition from traditional to online teaching during the COVID-19 pandemic. The study was limited to CHEIs providing accredited hospitality-related programs of study. Hence, the experiences of educators were investigated only concerning personal or interpersonal approaches. As such, educators from other programs and students participating in such research could have more informed perspectives about the digital element in higher education teaching and learning, limiting the generalization of the current study's findings.

Further research could expand on the quality assurance dimension and requirement to explore and discover possible gaps or weaknesses that affect a program's quality and accreditation standards. Thus, what were the positive or negative impacts on teaching and learning quality criteria and the expected course learning outcomes? Therefore, it would be more useful 
to confirm whether or not the successful personal and interpersonal responsiveness reflected the actual learning outcomes achieved.

\section{REFERENCES}

Alexander, B., Ashford-Rowe, K., Barajas-Murph, N., Dobbin, G., Knott, J., McCormack, M., \& Weber, N. (2019). EDUCAUSE Horizon Report 2019 Higher Education Edition. Louisville: CO: EDUCAUSE1-19. http://trendsandissues.org/node/455

American Library Association. (2016). American Library Association's digital-literacy task force. https://www.edweek .org/ew/articles /2016/11/ 09/ what-is-digital-literacy.html

Anastasiou, M. (2019). Mapping international students' expectations from the CY hospitality and tourism higher education: An early dropout indicator. Tourism and Hospitality Management, 25(2), pp. 269-290. https://doi.org/10.20867/thm.25.2.2

Batane, T., \& Ngwako, A. (2017). Technology use by pre-service teachers during teaching practice: Are new teachers embracing technology right away in their first teaching experience? Australasian Journal of Educational Technology, 33(1), pp. 48-62.https://ajet.org. au/index.php /AJET/article/view/2299

Becker, S. A., Cummins, M., Davis, A., Freeman, A., Hall, C. G., \& Ananthanarayanan, V. (2017). NMC horizon report: 2017 higher education edition. The New Media Consortium, 1-60.

Benson, V., \& Morgan, S, (2013). Student experience and ubiquitous learning in higher education: Impact of wireless and cloud applications. Creative Education, 4(8A), pp. 1-5. http://dx.doi.org /10.4236/ce.2 013.48A001

Blau, I., Shamir-Inbal, T., \& Avdiel, O. (2020). How does the pedagogical design of a technology-enhanced collaborative academic course promote digital literacies, self-regulation, and perceived learning of students? The Internet and Higher Education, 45, 100-722. https://doi.org/ 10.10 16/j.ihe duc.2019.100722

Bond, M., Marin, V. I., Dolch, C., Bedenlier, S., \& Zawacki-Richter, O. (2018). Digital transformation in German higher education: Student and teacher perceptions and usage of digital media. International Journal of Education Technology in Higher Education, 15(48), 1-20. https://doi.org/ 10.1186/s41239-018-0130-1 
Boulton, C. A., Kent, C., \& Williams, H. T. P. (2018). Virtual learning environment engagement and learning outcomes at a 'bricks-andmortar' university. Computer \& Education, 126, 129-142. https://doi.org/1 0.1016/j.compedu.2018.06.031

Buchanan, T., Sainter, P., \& Saunders, G. (2013). Factors affecting faculty use of learning technologies: Implications for models of technology adoption. Journal of Computing in Higher Education, 25, pp. 1-11. https://doi.org/10.1007/s12528-013-9066-6

Carretero, S., Vuorikari, R., \& Punie, Y. (2017). DigComp2.1: The Digital Competence Framework for Citizens with eight proficiency levels and examples of use (No.JRC106281). Joint Research Centre (Seville site). http://publications.jrc .ec.europa.eu/repos itory/handle/JR C106281Centers for Disease Control and Prevention 24/7. (2013). About severe acute respiratory syndrome (SARS): Ten years later. https://www.cdc.gov/sars/guidance/g-education/rationale.html

Cho, H. W., \& Chu, C. (2015). Outbreak of Middle East respiratory syndrome in Korea? Osong Public Health Res Perspect, 6, 4, pp. 219-223. doi:10.1016/j.phrp.2015.08.005

Colbert, A., Yee, N., \& George, G. (2016). The digital workforce and the workplace of the future. Academy of Management Journal, 59(3), 731-739. https://doi.org/10.5465/amj.2016.4003

Conference Board. (2019). Employability skills: The skills you need to enter, stay in, and progress in the world of work - whether you work on your own or as a part of a team. https://www. Conferenceboard .ca/edu/employability-skills.aspx?AspxAutoDetectCookieSupportZ1

Connolly, M., Jones, C., \& Jones, N. (2007). New approaches, new vision: Capturing teacher experiences in a brave new online world. Open Learning, 22(1), 43-56. https://doi.org/10.1080/02680510601100150

Cramphorn, C. (2004). An evaluation of formal and underlying factors influencing student participation within e-learning web discussion forums. Paper presented at the Networked Learning Conference 2004, Lancaster University.Cyprus Agency of Quality Assurance and Accreditation in Higher Education [CYQAA]. (2020).

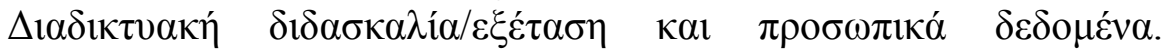
https://www.dipae.ac.cy/index.php/el/nea-ekdiloseis/anakoinoseis-el/51610-04-2020-distance-learning

Denzin, N. (2001). Interpretive interactionism (2nd ed.). Thousand Oaks, CA: Sage Publications Inc. 
Eshet-Alkalai, Y. (2012). Thinking in the digital era: A revised model for digital literacy. Issues in Informing Science and Information Technology, 9(2), 267-276. https://doi.org/10.28945/1621

European Centre for Disease Prevention and Control. (2014). Epidemiological update: Middle East respiratory syndrome coronavirus events/epide coronavirus-mers-cov- 0

(MERS-CoV).https://www.ecdc.europa.eu/en/newsmiological-update-middle-east-respiratory-syndrome-

European Migration Network. (2012). Immigration of international students to the EU. Cyprus Ministry of Interior. Republic of Cyprus. https://ec.europa.eu/home-affairs/sites/homeaffairs/files/

Ferrari, A. (2012). Digital competence in practice: An analysis of frameworks. Luxembourg: Publications Office of the European Union: JRC IPTS. https://doi.org/10.2791/82116

Flick, U. (2008). Designing qualitative research. New York, NY: Sage.

Forrester. (2015). Digital transformation in the age of the customer: A spotlight on insurance https://insuranceblog.accenture.com/wp-content/ uploads/2017/05/Digital-Transformation-in-the-Age-of-the-CustomerPOV.pdf

Garner, R., \& Rouse, E. (2016). Social presence - connecting pre-service teachers as learners using a blended learning model. Student Success, 7(1), 25-36. https://doi.org/10.5204/ssj.v7i1.299

Griffith, A. D., Morris, E. S., \& Thakar, V. (2016). Spatial autocorrelation and qualitative sampling: The case of snowball type sampling designs. Annals of the American Association of Geographers, 106(4), 773-787. doi:10.1080/24694452.2016.1164580

Guinan, J. P., Parise, S., \& Langowitz, N. (2019). Creating an innovative digital project team: Levers to enable digital transformation. $\begin{array}{llll}\text { Business Horizons } & \text { 62, } & \text { 717-727. }\end{array}$ https://doi.org/10.1016/j.bushor.2019.07.005

Hildebrandt, C. (2019). Whose interest is educational technology serving? Who is included and who is excluded? Revista Iberoamericana de Educación a Distancia.https://doi.org/10.5944/ried.22.1.22293

IDC. (2017, December 15). IDC forecasts worldwide spending on digital transformation technologies to reach $\$ 1.3$ trillion in 2018 . https://www.idc.com/getdoc.jsp?containerIdZprUS43381817 
Jackson, C. N. (2019). Managing for competency with innovation change in higher education: Examining the pitfalls and pivots of digital transformation. Business Horizons, 62, pp. 761-772. https:// doi.or g/10. 1016/j.bushor.2019.08.002

Jiang, X. (2009). The virtual SARS epidemic in Europe 2002-2003 and its effects on European Chinese. Health, Risk \& Society, 11(3), pp. 241256. doi:10.1080/13698570902887498

Kukulska-Hulme, A. (2012). How should the higher education workforce adapt to advancements in technology for teaching and learning? Internet and Higher Education, 15, 247-254. doi:10.1016/j.iheduc.2011.12.002

Lim, M. (2020). THE: World Ranking Universities: Educating despite the Covid-19 outbreak: Lessons from Singapore. https://www.timeshigher education.com/blog/educating-despite-covid-19-outbreak-lessonssingapore

Lincoln, Y. S., \& Guba, E. G. (2013). The constructivist credo. Walnut Creek, CA: Left Coast Press.

Mason, R., \& Bacsich, P. (1998). Embedding computer conferences into university courses. Computers \& Education 30, pp. 249-258. doi:10.1016/S0360-1315(97)00068-7

Mintel. (2020). Mintel's Global COVID-19 Tracker trends changes in global consumer behavior directly related to COVID-19. https://www.mintel.com/press-centre/40-of-americans-are-worried-aboutthe-impact-covid-19-will-have-on-their-lifestyle

Muñoz-Cristóbal, J. A., Gallego-Lema, V., Arribas-Cubero, H. F., MartínezMonés, A., \& Asensio-Pérez, J. (2017). Using virtual learning environments in bricolage mode for orchestrating learning situations across physical and virtual spaces. Computers \& Education, 109, 233-252. https://doi.org/10.1016/j.compedu.2017.03.004

Nachmias, S., Walmsley, A., \& Orphanidou, Y. (2017). Students' perception towards hospitality education: An anglocypriot critical study. Journal of Hospitality, Leisure,Sport \& Tourism Education, 20, pp. 134-145. doi.org/10.1016/j.jhlste.2017.04.007

$\mathrm{Ng}$, W. (2012). Can we teach digital natives digital literacy? Computers \& Education, 59(3), 1065-1078.

Ngambi, D., Brown, C., Bozalek, V., Gachago, D., \& Wood, D. (2016). Technology enhanced teaching and learning in South African higher education - A rearview of a 20-year journey. British Journal of 
Educational Technologies, 47(5), pp. 843-858. https:// doi.or g/10.1 111/bjet. 12485

Noy, C. (2008). Sampling knowledge: The hermeneutics of snowball sampling in qualitative research. International Journal of Social Research Methodology, 11(4), 327-344. https://nbnresolving.org/urn:nbn:de:0168-ssoar-53861

Ocak, M. A., (2011). Why are faculty members not teaching blended courses? Insights from faculty members. Comput. Educ., 56(3), 689-699. https://doi.org/10.1016/j.compedu.2010.10.011

Patton, M. Q. (2015). Qualitative research \& evaluation methods (4th ed.). Thousand Oaks,CA: Sage Publications Inc.

Press and Information Office. (2020). The President of the Republic addresses the Cyprus people on the issue of Coronavirus. 13-032020. https://www.pio.gov.cy/en/press-releases-article.html?id=12649\#flat

Porat, E., Blau, I., \& Barak, A. (2018). Measuring digital literacies: Junior high-school students' perceived competencies versus actual performance. Computers \& Education, 126, 23-36. https://doi .org /10.1 016/ j.co mpe du.2018.06.030

Porter, E. J., Barbagallo, S. M., Peck, B., Allen, L., Tanti, E., \& Churchill, A. (2020). The academic experiences of transitioning to blended online and digital nursing curriculum. Nurse Education, 87, 104361. https://doi.org/10.1016/j.nedt.2020.104361

Pucciarelli, F., \& Kaplan, A. (2016). Competition and strategy in higher education: Managing complexity and uncertainty. Business Horizons, 59(3), 311-320. https://doi.org/10.1016/j.bushor.2016.01.003

Radianti, J., Majchrzak, A. T., Fromm, J., \& Wohlgenannt, I. (2020). A systematic review of immersive virtual reality applications for higher education: Design elements, lessons learned, and research agenda. Computer \& Education, 147, 103778. https://doi.o rg/10.1 016/j .compedu .2019.103778

Rasheed, A. R., Kamsin, A., \& Abdullah, A. N. (2020). Challenges in the online component of blended learning: A systematic review. Computer \& $\quad$ Education, 103701. https://doi.org/10.1016/j.compedu.2019.103701

Redecker, C. (2017). European Framework for the Digital Competence of Educators: DigCompEdu. EUR 28775 EN. Luxembourg: Publications Office of the European Union. https: //publications .jrc.ec.eur opa.eu/re pository/b itstream /JRC107 466/pdf_ digcomedu_a4_fin al.pdf 
Richlin, L. \& Cox, D. M. (2004). Developing scholarly teaching and the scholarship of teaching and learning through faculty learning communities. New Directions for Teaching and Learning, 97, pp. 127-135. doi:10.1002/tl.139

Schadler, T. (2018). The sorry state of digital transformation in 2018. Cambridge, MA: Forrester Research.

Schwarzmuller, T., Brosi, P., Duman, D., \& Welpe, I. M. (2018). How does digital transformation affect organizations? Key themes of change in work design and leadership. Management Revue, 29(2), 114-138. doi:10.5771/0935-9915-2018-2-114

Sohrabi, C., Alsafi, Z., O’Neill, N., Khan, M., Kerwan, A., Al-Jabir, A., Iosifidis, C., Agha, R. (2020). World Health Organization declares global emergency: A review of the 2019 novel coronavirus (COVID19). International Journal of Surgery, 76, pp. 71-76. https://doi.org /10.10 16/j.ijsu.2020.02.034

Solıs-Molina, M., Hernandez-Espallardo, M., \& Rodrıguez-Orejuela, A. (2018). Performance implications of organizational ambidexterity versus specialization in exploitation or exploration: The role of absorptive capacity. Journal of Business Research, 91, 181-194. doi:10.1016/j.jbusres.2018.06.001

Stake, R. E. (2010). Qualitative research: Studying how things work. New York, NY: The Guilford Press.

Wang, R., Wiesemes, R., \& Gibbons, C. (2012). Developing digital fluency through ubiquitous mobile devices: Findings from a small-scale study. Computers \& Education, 58, pp. 570-578. doi:10.1016/j.compedu.2011.04.013

Warburton, S. (2009). Second life in higher education: Assessing the potential for and the barriers to deploying virtual worlds in learning and teaching. British Journal of Educational Technology, 40(3), pp. 414426. https://doi.org/10.1111/j.1467-8535.2009.00952.x

World Health Organization. (2020). Novel Coronavirus(2019-nCoV), Situation Report - 12.

Yin, R. K. (2017). Case study research and applications: Design and methods (6th ed.). New York, NY: Sage Publications.

Zawacki-Richter, O. \& Latchem, C. (2018). Exploring four decades of research in Computers \& Education. Computers \& Education, 122, pp. 136-152. https://doi.org/10.1016/j.compedu.2018.04.001 